\title{
A bipolaridade da crise sanitária: sofismas economicistas e impactos sociais na pandemia do coronavírus
}

\section{| ${ }^{1}$ Marcia Silveira Ney, ${ }^{2}$ Carlos Alberto Grisólia Gonçalves |}

\author{
${ }^{1}$ Instituto de Medicina Social, Universidade do Estado do Rio de Janeiro. Rio de Janeiro-RJ, Brasil (marcia.ney.unesa@gmail.com). ORCID: \\ 0000-0002-3262-565X \\ ${ }^{2}$ Instituto de Medicina Social, Universidade do Estado do Rio de Janeiro. Rio de Janeiro-RJ, Brasil. ORCID: 0000-0003-2157-4997 \\ Recebido em: 21/04/2020 \\ Aprovado em: 25/04/2020 \\ Revisado em: 27/04/2020
}

DOI: http://dx.doi.org/10.1590/S0103-73312020300212

O Brasil e o mundo enfrentam uma das piores situaçóes de emergência de saúde pública no início de 2020. A Organização Mundial da Saúde (OMS) emitiu, em 30 de janeiro, a declaração de emergência em saúde pública de Importância Internacional por Infecçáo Respiratória Aguda pelo Novo Coronavírus (SARS - CoV-2). No Brasil, o Ministério da Saúde declarou emergência em saúde pública de importância nacional em 3 de fevereiro. A pandemia foi oficializada pela OMS em 11 de março. No Brasil, o primeiro caso da doença foi notificado em 26 de fevereiro de 2020 e a primeira morte em 17 de março, ambos no estado de Sáo Paulo. No estado do Rio de Janeiro, o primeiro caso notificado foi em 5 de março. No dia 20 de março, a doença já era considerada como de transmissáo comunitária em todo país. ${ }^{1}$

O novo coronavírus é uma doença que se propaga rapidamente e que requer imediatas intervençôes nos sistemas de saúde de cada país atingido. Questóes cruciais sobre o sistema econômico, os modelos de intervenção estatal e, especificamente, dos sistemas sanitários dos países pelo mundo vieram a primeiro plano na discussão pública. Diante de um vírus, cujo comportamento ainda se desconhece, pouco se pode afirmar e estabelecer padrôes de evoluçáo da doença, assim como da assustadora progressão de contágio e número de vítimas fatais (não em função da letalidade em 
si, mas pela capacidade dos sistemas de saúde de impedir óbitos, efeitos diretos e indiretos do vírus pela necessidade de recursos imediatos para o atendimento às vítimas), as recomendaçóes primárias, o pouco consenso que se pode formar no meio científico e as recomendaçóes estabelecidas pela OMS para o controle da pandemia se convencionaram na prática da higiene preventiva e o isolamento social horizontal.

Com a instituição do isolamento de todos com manutenção apenas de serviços essenciais, em vistas da distribuição do número de infectados ao decorrer do tempo para não sobrecarregar o sistema de saúde diante da transmissão comunitária sustentada, ressurge a polarizaçáo no discurso político sobre as prioridades na crise sanitária (entre): manter o funcionamento da economia para prevenir os efeitos drásticos futuros ou seguir a recomendação da OMS e das autoridades sanitárias de suspensão de todos os setores não essenciais para prevenir mortes desnecessárias.

A primeira direção se apoiaria em um cenário no qual nosso país já enfrenta há alguns anos um quadro de desemprego, aumento expressivo da informalidade do trabalho e da pobreza, com consequente deterioração das condiçóes de vida da população (de moradia, acesso a direitos básicos, opressão pela violência, entre outros fatores) e que parar a economia potencializaria uma tragédia já em curso. Um argumento que se baseia "(n)o medo da fome, no trabalhador, e a atração do lucro do empregador [...]” (POLANYI, 2012, p. 54), uma lógica restrita que, segundo o filósofo social Karl Polanyi (2012, p. 54.), privilegia uma perspectiva de mercado em detrimento das questôes sociais e culturais, tomando as próprias causas dos efeitos nefastos das medidas liberais como sua solução. O grupo que defende essa posição toma parte no coro das promessas obscurantistas de reforma do sistema de proteção social brasileiro (de restrição dos direitos trabalhistas, previdenciários e demais políticas sociais do Estado brasileiro) que precederam e agravaram os problemas estruturais antes da crise atual. Dito de outra forma, a habitual narrativa de sequestro das perspectivas de futuro da maior parte da sociedade, que sugestionada por argumentos de autoridade acaba por apoiar a perda de seus direitos, convencidos de que serão recompensados no futuro.

A segunda direção lança a questão sobre a capacidade dos governos em responderem com eficácia a um vírus de contágio acelerado - do qual não há agente intermediário como vetor, o que configura um fator agravante - e quais são as instituiçôes públicas ou privadas que poderão cumprir essa tarefa. Lança a 
questấo (de uma obviedade tautológica, note-se) de que, em uma crise sanitária, serão as medidas sanitárias que poderão debelá-la, e que a redução a uma questão econômica (em um sentido estrito de mercado) ocasionará perdas maiores em vida e para a própria economia no futuro. ${ }^{2}$ É o status de cidadania, o direto social que está em questáo: "O elemento social se refere a tudo o que vai desde o direito de um mínimo de bem-estar econômico e segurança ao direito de participar, por completo, na herança social e levar a vida de um ser civilizado de acordo com os padróes que prevalecem na sociedade" (MARSHALL, 1967, p. 63-64). No contexto brasileiro, entre urgências sanitárias que se alternam, o Sistema Único de Saúde (SUS) retoma o lugar de destaque e transita da posição de alvo do linchamento midiático, de crítica à ineficiência do Estado e justificativa de medidas de austeridade, para seu status de cidadania, representante do interesse público e de deveres constitucionais.

O que se impõe nessa conjuntura não é só o que se refere ao período agudo que o mundo atravessa, mas os problemas crônicos que o assolam desde a década de 1980, do século passado - principalmente no hemisfério ocidental - e que dizem respeito à função dos Estados na economia (e a quem servem), a deterioração do mundo do trabalho e dos pactos solidários das políticas sociais. De saída, as medidas adotadas pela maioria dos países desenvolvidos se centraram no aumento expressivo do gasto público, na estatização de equipamentos privados, na adaptação do setor industrial para produção de insumos necessários ao combate ao vírus e no prestígio social alçado pelos trabalhadores efetores dessas medidas ${ }^{3}$ (os funcionários públicos), ou seja, uma reconfiguração do que até então se apresentava estabelecido como as funçôes essenciais do Estado. Mediante um "novo normal”, são os valores coletivos que se reforçam, e escapar da dinâmica de mercado pode significar sobreviver.

O debate em evidência na atual crise sanitária remete aos problemas sociais (humanos) crônicos. A questão humana ganha um privilégio inverso na pandemia: este é um vírus que afeta mulheres e homens. Os outros animais ${ }^{4}$ e a natureza não são afligidos pela doença - ao contrário, há diminuição nos índices de poluição e, muito provavelmente, nos danos à vida animal. É o nosso modo de vida, exclusivamente nosso, que está em questão. Observamos, tal qual é possível notar em tragédias naturais mais pontuais, uma rede de solidariedade que se forma espontaneamente no intuito do amparo mútuo na sociedade. É, mais uma vez, Polanyi (2016) quem nos oferece uma chave de compreensão sobre 
as possibilidades de frente aos impasses forjados entre o futuro da economia e da humanidade (como se pudesse haver um sem o outro):

Os aspectos puramente econômicos, como os que se referem à satisfação das necessidades
materiais, são incomparavelmente menos relevantes em termos de comportamento de
classe do que as questóes de reconhecimento social. A satisfação das necessidades poderá
ser, como é óbvio, o resultado do reconhecimento - nomeadamente, na forma de seu sinal
exterior ou de sua recompensa. Mas os interesses de uma classe reportam-se, sobretudo,
ao estatuto e à condição, ao prestígio e à segurança, o que faz com que não sejam princi-
palmente econômicos, mas sociais (POLANYI, 2016, p. 328).

Segundo a Organização para a Cooperação e Desenvolvimento Econômico, o mundo levará anos para se recuperar do impacto sofrido devido à pandemia do coronavírus. No Brasil, segundo estudo da Fundação Getúlio Vargas, o PIB pode recuar 4,4\% em 2020. O Fundo Monetário Internacional também calcula que a economia global deverá ter o pior desempenho desde a Grande Depressão em 1929.

Essas projeçôes nos colocam a tarefa de repensar os parâmetros de cidadania que adotamos antes da crise e quais caminhos serão seguidos após esse período. Se a pandemia deflagrou uma reflexão forçada sobre quais serviços são essenciais, nestes inclusos a saúde e a assistência social (segundo o artigo terceiro, parágrafo primeiro do Decreto no 10.282, de 20 de março de 2020), dentre outros, é preciso reexaminar por que essas são áreas que foram minadas progressivamente antes de serem resgatadas como essenciais. No caso da saúde que já sofria com o subfinanciamento crônico, teve seus investimentos congelados por 20 anos pela Emenda Constitucional $\mathrm{n}^{\circ}$ 95; as políticas de assistência social se consolidam gradualmente por critérios de miserabilidade com benefícios mínimos, ocupando o status de cidadania desejável de outras políticas de caráter universal (renda mínima, proteção social às mulheres, ao emprego, etc.).

Os princípios que regiam os governos recentes na administração da proteção social do Estado brasileiro há muito se direcionam para achatar a curva de afetados ao longo do tempo, administrando uma sustentabilidade exclusiva e relegando o insustentável com recortes específicos de classe, gênero e raça. Se achatar a curva é uma medida necessária, que marca nossa insufi(ciência) diante de uma crise aguda, com o objetivo de salvaguardar o máximo de vidas possível, em tempos de normalidade, com todo o peso que o funcionamento "normal" pode ter para algumas vidas, marca um posicionamento político ideológico claro, de um sistema que escolhe quem deve viver e quem pode morrer. 


\section{Referências}

BRASIL. Decreto no 10.282, de 20 de março de 2020. Regulamenta a Lei no 13.979, de 6 de fevereiro de 2020, para definir os serviços públicos e as atividades essenciais. DOU-Diário Oficial da União, Seção 1, Brasília - DF, Publicado em: 21 mar. 2020, Edição: 55-H, Seção: 1 - Extra, p. 1.

BRASIL. Ministério da Saúde. Agência Saúde. Ministério da Saúde declara transmissão comunitária nacional. 20 de março de 2020, 22:05h. Disponível em: <https://www.saude. gov.br/noticias/agencia-saude/46568-ministerio-da-saude-declara-transmissao-comunitarianacional>. Acesso em: 30 mar. 2020.

BRASIL. Ministério da Saúde. Painel Coronavirus de Dados. Disponível em: <https://covid. saude.gov.br/>. Acesso em: 31 mar. 2020.

GERBELLI, L. G. Com coronavírus, economia global deve ter pior desempenho desde a Grande Depressão, diz FMI. G1.14/04/2020. Disponível em: <https://g1.globo.com/economia/ noticia/2020/04/14/com-coronavirus-economia-global-deve-ter-pior-desempenho-desde-agrande-depressao-diz-fmi.ghtml>. Acesso em: 19 abr. 2020.

ENTENDA os impactos da pandemia de coronavírus nas economias global e brasileira. G1. 26/02/2020. Disponível em: <https://g1.globo.com/economia/noticia/2020/02/26/entendaos-impactos-do-avanco-do-coronavirus-na-economia-global-e-brasileira.ghtml>. Acesso em: 19 abr. 2020.

MARSHALL, T. H. Cidadania, classe social e status. Tradução: Meton Porto Gadelha. Rio de Janeiro: Zahar editores, 1967, 220 p.

POLANY, K. A grande transformação: as origens politicas e econômicas de nosso tempo. Tradução: Miguel Serras Pereira. Lisboa: Edições 70, 2016, 554 p.

POLANY, K. A subsistência do homem e ensaios correlatos. Tradução: Vera Ribeiro. Rio de Janeiro: Contraponto, 2012, 382 p.

\section{Notas}

${ }^{1}$ Disponível em: <Ministério da Saúde. Agência Saúde. Ministério da Saúde declara transmissão comunitária nacional.https:/www.saude.gov.br/noticias/agencia-saude/46568-ministerio-da-saude-declara-transmissao-comunitaria-nacional: >. Acesso em: 20 mar. 2020.

${ }^{2}$ Essa proposição se posiciona contra as falas sociopáticas de alguns empresários brasileiros que exigiram, ou banalizaram, a morte de alguns milhares de pessoas como um sacrifício necessário ao bom andamento da economia durante e pós a pandemia. Disponíveis em: < https://istoe.com.br/dono-do-madero-diz-que-brasil-nao-pode-parar-por-5-ou-7-mil-mortes/ >; <https://economia.uol.com.br/noticias/ redacao/2020/03/24/empresarios-coronavirus-o-que-dizem-criticas.htm >; <https://www.msn.com/pt-br/entretenimento/famosos/vamos-ter-muito-mais-falidos-do-que-gente-morta-reafirma-roberto-justus/ ss-BB11KaAu > . Acesso em: 20 abr. 2020. 
${ }_{3}^{3}$ Assim como mostram as diversas homenagens no Brasil e ao redor do mundo. Disponíveis em: < https:// g1.globo.com/pr/parana/noticia/2020/04/08/grafite-em-homenagem-a-profissionais-da-saude-durante-pandemia-viraliza.ghtml >; < https://g1.globo.com/df/distrito-federal/noticia/2020/03/20/coronavirus-servidores-da-saude-do-df-agradecem-homenagens-e-reforcam-importancia-do-sus.ghtml $>$; < https:// oglobo.globo.com/rio/pm-homenageia-profissionais-de-saude-por-trabalho-durante-pandemia-do-coronavirus-24336553 > ; https://oglobo.globo.com/fotogalerias/manifestacoes-de-amor-ao-nhs-sus-britanico-tomam-conta-do-reino-unido-24383054 >. Acessos em: 19 abr. 2020. Entre vários.

${ }^{4}$ Até a escrita deste artigo, não havia nenhuma evidência científica, salvo ínfimos casos isolados de adoecimento de animais, que os mesmos constituíam um vetor de transmissão do novo coronavírus. 